\title{
Water quality status of recreational spots in Chittagong City
}

\author{
Md. Lokman Hossain ${ }^{1, ~ *, ~ S u l t a n a ~ K a m r u n ~ N a h a r ~ N a h i d a ~}{ }^{2}$, Md. Iqbal Hossain ${ }^{2}$ \\ ${ }^{1}$ Department of Global Change Ecology, Faculty of Biology, Chemistry and Geosciences, University of Bayreuth, D-95440 Bayreuth, \\ Germany \\ ${ }^{2}$ Institute of Forestry and Environmental Sciences, University of Chittagong, Chittagong 4331, Bangladesh
}

Email address:

lokmanbbd@gmail.com (M. L. Hossain), sknnahida@gmail.com (S. K. N. Nahida), iqbal.sohag@gmail.com (M. I. Hossain)

\section{To cite this article:}

Md. Lokman Hossain, Sultana Kamrun Nahar Nahida, Md. Iqbal Hossain. Water Quality Status of Recreational Spots in Chittagong City. Journal of Water Resources and Ocean Science. Vol. 3, No. 3, 2014, pp. 38-44. doi: 10.11648/j.wros.20140303.12

\begin{abstract}
The study was conducted to learn about water quality status at potential recreational spots in Chittagong City. Water samples were collected from six recreational spots. Derived parameters namely; Conductivity, Turbidity, Color, Odor, pH, Dissolve Oxygen (DO), Biological Oxygen Demand (BOD), Chemical Oxygen Demand (COD), Sulfate and Nitrate of the collected water samples were compared with the standard value of the respective parameters. The study revealed that water conductivity of Karnafully Shishu Park $(1400 \mu \mathrm{s} / \mathrm{cm})$ and Jatisongho Park $(1430 \mu \mathrm{s} / \mathrm{cm})$ could satisfy the standard level $(1500 \mu \mathrm{s} / \mathrm{cm})$ and the other spots exceeded the limit. Water collected from Foy's lake was a bit turbid (5.07 ntu) but it did not significantly exceed the expected limit ( $5 \mathrm{ntu}$ ). The study also revealed that water of Foy's Lake was darker (55 Hazen) compared to the standard (20 Hazen). In case of odor, all the spots' water was unobjectionable except Chittagong Shishu Park and Jatisongho Park. BOD and DO content were satisfactory for all the spots. But COD was higher at Chittagong Shishu Park, Karnafully Shishu Park and Zia Smriti Complex. Nitrate concentration was also found satisfactory in water of all spots except Chittagong Shishu Park (19.33 ppm). All the parameters were under the desired levels for recreation with few exceptions. Although very small, to extend the recreational facilities for the urban people, these unwanted level of different physical and chemical parameters should be mended on an urgent basis.
\end{abstract}

Keywords: Biological Oxygen Demand, Chemical Parameter, Dissolved Oxygen, Water Quality

\section{Introduction}

The earth is covered by approximately $71 \%$ of water but only a total of $3 \%$ is fresh water, of which only $0.003 \%$ of freshwater is accessible to humans [1]. Around 1.2 billion people or almost one-fifth of the world's population lives in areas of physical water scarcity [2]. Water is an indispensable and one of the most precious of natural resources on this planet [3]. Water is inevitable to plant growth [4,5] and sustaining animal life [6] as well as it is the predominant inorganic constituents of living matter, forming in general nearly three quarters of the weight of the living beings [7-9]. For every living system the presence or provision of water is consequently of cardinal importance. Water is abundant in the liquid form and large quantities exist as gas (vapor) and in the form of ice and snow [10]. Water resources are one of the most critical and a valuable component of the resources of nation [11]. With marked rise in population, the demand of pure water is gradually increasing. Still now, nearly two thirds of the population does not have reasonable access to safe and ample water supply [12]. Water pollution is a phenomenon that is characterized by the deterioration of the quality of land water or seawater as a result of human activities. Human activities related with water pollution such as human mining, agriculture, stockbreeding, fish farming, forestry, urban activities, manufacturing industry, construction works and various territory industries [10]. Water pollution is a global problem, affecting both the industrialized and the developing nations. The water pollution problem in the rich and poor nations, however, is quite different in many respects [10]. The primary quality of water is vital concern for mankind and other living organisms, since it is directly related with human habitation and welfare. The quality of domestic water is most important in this respect. But hazards of water cause water born diseases epidemic still looms 
largely on the horizons of developing countries like Bangladesh [13]. The quality of water is one of the vital concerns for mankind since it is directly linked with human welfare [14].

Water quality concerns have often been neglected because good quality water supplies have been plentiful and readily available. The situation is now changing in many areas of the world including Bangladesh [4,15-17]. Water is used as a chemical, solvent, source of energy, coolant, transportation medium, a recreational base, habitat for fish and wildlife, a silvicutural and agricultural raw material and agent for waste removal [18]. Safe wholesome water is that free from pathogenic agents, harmful chemical substances, pleasant to taste usable to domestic and recreational purposes [19]. Recreational waters refer to those natural waters used not only for primary contact activities, such as swimming, windsurfing, and waterskiing, but also for secondary contact activities, such as boating and fishing [20]. Good quality recreational water is an essential part of the natural ecosystem. Recreational exposure to surface waters during periods of increased pathogen concentration may lead to a significantly higher risk of illness [21]. Maintaining safe recreational waters requires a concentrated effort from all of its stakeholders. From government at all levels, to local businesses and industry, to community members, all have a role to play in helping to keep recreational waters safe [20]. It is necessary to monitor water qualities of recreational water whenever these are used for recreational purpose. Considering the importance of recreation in urban life the present study was designed to measure the water quality of recreational spots.

\subsection{Background Information of the Study Area}

Chittagong is the gateway and the second largest city of Bangladesh [22] with a substantial, self-sustaining economic base [23]. Chittagong lies between latitude $22^{\circ} 14^{\prime} \mathrm{N}$ and $22^{\circ} 24^{\prime} \mathrm{N}$ longitude $91^{\circ} 46^{\prime} \mathrm{E}$ and $91^{\circ} 53^{\prime} \mathrm{E}$ [22] and stands on the bank of the river Karnafully. It is situated at the extreme southeastern part of the country. It comprises about 209.66 sq $\mathrm{km}$ [22]. It is upgraded as Municipal Corporation and finally as City Corporation in 1990 [24]. Urbanization and population growth rate is high in Chittagong city [25]. Chittagong is considered the crowning glory of Bangladesh for its some picturesque sites and elements of recreation. That is, Chittagong is replete with elements of recreation. The land, the rivers and the forests: these celestial beauties are the main elements of recreation in Chittagong. But the most unfortunate thing is that there are no scientific and systematically managed recreation spots. Chittagong is among those famous four places in the world where hills, rivers and seas are within the reach of just $10 \mathrm{~km}$ [26]. People flock in these places in a great number to get their holiday's comfort. However, very few works were done about recreational facilities in Chittagong. Thus, the study was undertaken to find out the recreational water quality in major recreational spots in Chittagong.

\subsubsection{Foy's Lake}

Foy's Lake is one of the prominent ornamental in Chittagong. It is considered as one of the most lucrative recreation spots of the city because of its extraordinary scenic beauty. It is situated $3 \mathrm{~km}$ north west of Chittagong City at Zakir Hossain Road. It is a naturally attractive landscape and stream area with hill ranges and gentle slope approximately 66 under above sea level running north-south director [27]. Foy's lake, a magnificent and natural scenic area with fascinating landscape green coverage of hills and blue water has become the most important criteria for recreation. The total area of the lake is 336.61 acres and others 3.55 acres. The resort surrounding the lake was first established in 1925.

\subsubsection{Chittagong Shisu Park}

Chittagong Shisu Park is the first man made well-designed recreational children park. It was inaugurated on November 28, 1994 at Kajir Dewri adjacent to Circuit House \& Zia Smriti Museum. Total area of the park is 3 acres. Though the park was designed especially for children a number of young and aged people usually visit the park for passing their leisure period. One fourth of the park is remained as green cover.

\subsubsection{Karnafuly Shisu Park}

Karnafuly Shisu Park is the potential children park in the Chittagong City. It was inaugurated on 16 December, 2000. Total area of the park is 9 acres. Although there is a limitation of space, a number of facilities are provided for recreation of children. Though the park was designed especially for children a number of young and aged people usually visit the park for passing their leisure period.

\subsubsection{Zia Smriti Complex}

$\mathrm{Zia}$ Smriti Complex is the prospective place of interest for particular in recreation. The complex is situated at the opposite site of the Baddarhat bus terminal, Chittagong. The total area of this complex is 23 acres.

\subsubsection{Jatisongho Park}

Jatisongho Park is the impending park for all age groups of Chittagong City. It is situated at Panchlaish residential area in the City. Total area of the park is 2 acres. Although there is a limitation of space, a number of facilities are provided for recreation of city dwellers. Young and aged people of the city usually visit the park for passing their leisure period.

\subsubsection{Vatiary Lake}

Vatiary Lake is one of the most attractive lakes in Chittagong. It is the great source of green space. Psychologists, sociologist and mass people agree on the view that the quality of urban life depends largely on the amount and quality of green spaces within it or close to it. This green space, when it exists, is usually occupied with lake, which, apart from this aesthetic value, are increasingly considered to play a vital role in the protection of the urban environment [28]. 


\section{Materials and Methods}

\subsection{Chemicals and Equipment Used}

The chemicals used for parameter test include $\mathrm{KI}$ and $\mathrm{MnSO}_{4}$, concentrated $\mathrm{H}_{2} \mathrm{SO}_{4}$, stretch as indicator, $\mathrm{Na}_{2} \mathrm{~S}_{2} \mathrm{O}_{3}$ (0.005), Alkali-iodide-Azide, buffer solution. The equipments which were used for parameter test include $\mathrm{pH}$ meter, pipette, burette, conical flask, cylinder, beaker, filter paper, evaporating disk, desiccators, electrical balance, BOD bottle, COD incubator, hot plate etc.

\subsection{Field Collection}

Nine water samples were collected from every recreational spot (total 90 samples from 10 recreational spots) as grab sampling method during March to May 2008. For proper assessment of water quality parameters, the samples were taken carefully. It was tried to make the samples representative in nature.

\subsection{Analysis of Samples}

The water samples were tested in the laboratory of the Institute of Forestry and Environmental Sciences, University of Chittagong and laboratory of Mohara Water Treatment Plant under Chittagong WASA, Chittagong, Bangladesh. Ten water parameters namely; $\mathrm{pH}$, Conductivity, DO, BOD, COD, Sulphate, Nitrate, Color, Turbidity and Odor were tested to assess the suitability of water for recreational use. The obtained value was compared with the standard value of different parameters for recreational purpose. The water quality parameters have been analyzed following the standard analytical methods.

\section{Result and Discussion}

\subsection{Physical Parameters}

\subsubsection{Conductivity}

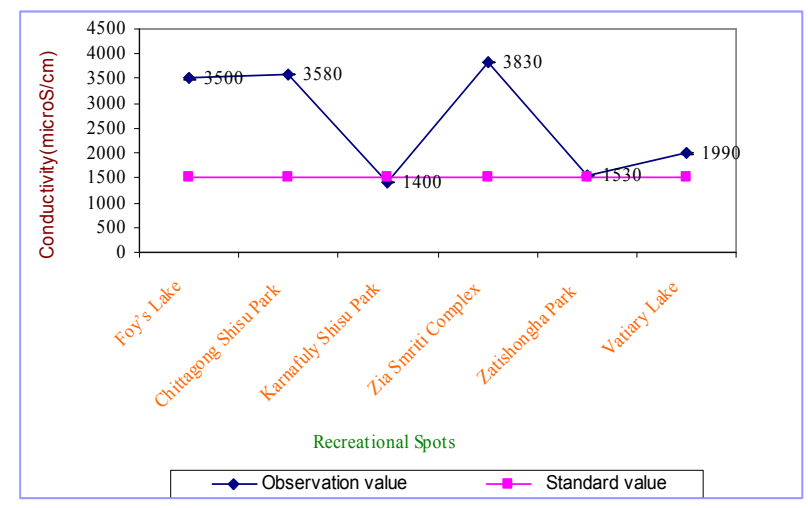

Figure 1. Conductivity of Water at Different Recreational Spots Compared with the Standard Value.

The study revealed that most of the recreational spot's water contains higher conductivity compared to standard value except Karnafully Shisu Park. The highest (3840 $\mu \mathrm{s} / \mathrm{cm})$ and lowest $(1400 \mu \mathrm{s} / \mathrm{cm})$ water conductivity were in Zia Smriti Complex and Karnafully Shisu Park respectively. The concentration of water conductivity of Foy's Lake, Chittagong Shisu Park and Zia Smriti Complex was about two and half times greater than that of standard value, which is very objectionable from the recreational point of view. The water conductivity of other two recreational spots namely; Vatiary Lake $(1530 \mu \mathrm{s} / \mathrm{cm})$ and Jatisongho Park $(1990 \mu \mathrm{s} / \mathrm{cm})$ also exceeded the permissible limit (Fig. 1). Therefore, for the safe use water as recreational purposes it should be maintained the standard value of conductivity in water.

\subsubsection{Turbidity}

Among the six recreational spots, turbidity in water in five spots found lower than the standard value $(5 \mathrm{ntu})$. The highest $(5.07 \mathrm{ntu})$ and lowest $(0.20 \mathrm{ntu})$ turbidity were calculated in the water of Foy's Lake and Zia Smriti Complex respectively. Turbidity of Chittagong Shisu Park, Karnafully Shisu Park, Jatisongho Park and Vatiary Lake were $2.57 \mathrm{ntu}, 1.93 \mathrm{ntu}, 0.97 \mathrm{ntu}$ and $0.87 \mathrm{ntu}$ respectively (Fig. 2). Foy's lake water should be treated as it exceeded the standard value.

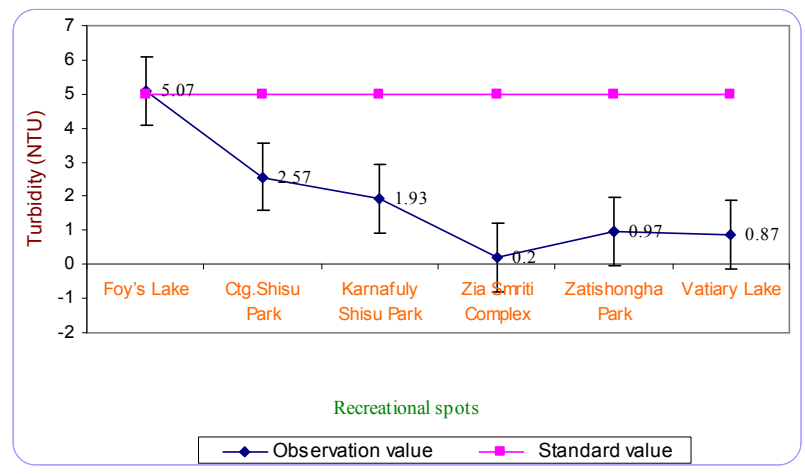

Figure 2. Turbidity of Water at Different Recreational Spots Compared with the Standard Value.

\subsubsection{Color}

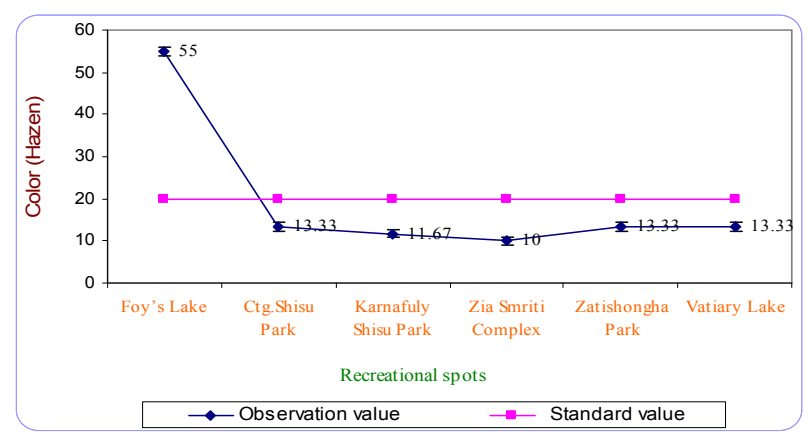

Figure 3. Color of Water at Different Recreational Spots Compared with the Standard Value.

The standard value of color of water is 20 Hazen [20]. The observation value of water color of six different recreational spots was not varied significantly at $1 \%$ level of significance. The highest (55 Hazen) value was found in the water of 
Foy's Lake whereas; lowest (10 Hazen) was in Zia Smriti Complex (Fig. 3). The observation value was same (13.33 Hazen) in three recreational spots namely, Chittagong Shisu Park, Jatisongho Park and Vatiary Lake (Fig. 3). Therefore, from the findings it can be recommended that water of the Foy's lake is not suitable for the recreational use.

\subsubsection{Odor}

Odor is one of the important parameter of water, should be considered for the recreational purposes. From the recreational point of view water must be odorless. The study revealed that water of Chittagong Shisu Park and Jatisongho Park generates odor, resulting the objectionable state. Odor is arisen due to the presence of organic matters, mineral matters and microbial residues. Odor is mainly generates due to prolonged stagnant condition of water and massive alteration of water chemical parameters. To ensure the odor free water, the first and foremost task is that water should free from all sorts of organic and minerals. Since two recreational spots provides odorous breathtaking so, it is an obvious task for the concerned authority to remove odor from water for safe use of water for recreational purposes.

Table 1. Odor of Water at Different Recreational Spots Compared with the Standard Value.

\begin{tabular}{lll}
\hline Spots & Observation value & Standard value \\
\hline $\begin{array}{l}\text { Foy's Lake } \\
\text { Chittagong Shisu }\end{array}$ & Unobjectionable & \\
$\begin{array}{l}\text { Park } \\
\text { Karnafully Shisu Park }\end{array}$ & Unobjectionable & \\
Zia Smriti Complex & Unobjectionable & \\
Jatisongho Park & Objectionable & \\
Vatiary Lake & Unobjectionable & \\
\hline
\end{tabular}

\subsection{Chemical Parameters}

\subsection{1. $\mathrm{pH}$}

The standard value of $\mathrm{pH}$ in the recreational water lies between 6.5 and 8.5 [20]. The highest (5.9) $\mathrm{pH}$ value was in the water of Vatiary Lake while, lowest (5.3) was in Jatisongho Park and Chittagong Shisu Park. $\mathrm{pH}$ in water of three recreational spots namely, Foys Lake, Karnafully Shisu Park and Zia Smriti Complex was given the same value (5.5) (Fig. 4). Therefore, from the observation it can be concluded that water of all of the recreational spots is acceptable for recreational purposes in respect of $\mathrm{pH}$. The water of Jatisongho Park and Chittagong Shisu Park contains lower $\mathrm{pH}$ because water of those spots contains higher organic wastes in comparison with other spots and hence these waste matters, through the decomposition, releases acidic substances to water, accelerate the lowering the value $\mathrm{pH}$.

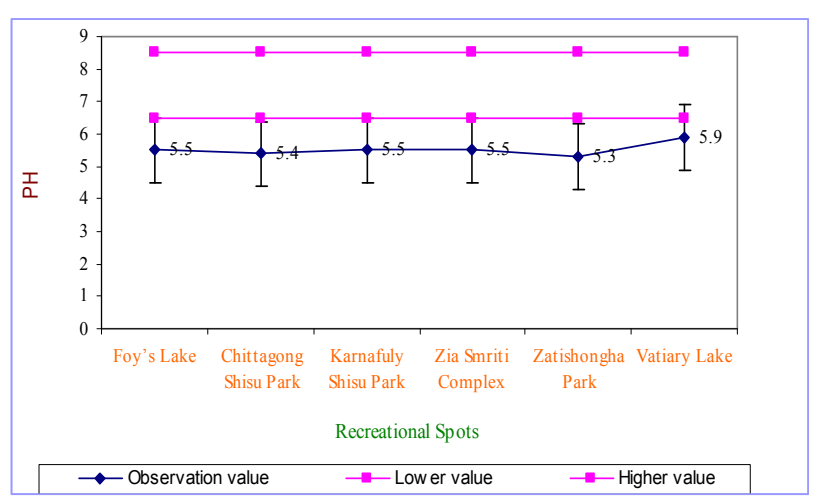

Figure 4. $p H$ of Water at Different Recreational Spots Compared with the Standard Value.

\subsubsection{Dissolve Oxygen (DO)}

The higher the value of DO in water than standard value means greater is the acceptability of that water. That means higher the value of DO content of water, higher will be the transparency of water. The study revealed that the observed values of DO in water of different recreational sites were higher than standard value $(4 \mathrm{mg} / \mathrm{L})$ specified for recreational usage [29]. The observation values varied between $10.17 \mathrm{mg} / \mathrm{L}$ in Foy's Lake and $11.12 \mathrm{mg} / \mathrm{L}$ in Jatisongho Park (Fig. 5). The DO content in water of recreational spots was not varied at $1 \%$ level of significance.

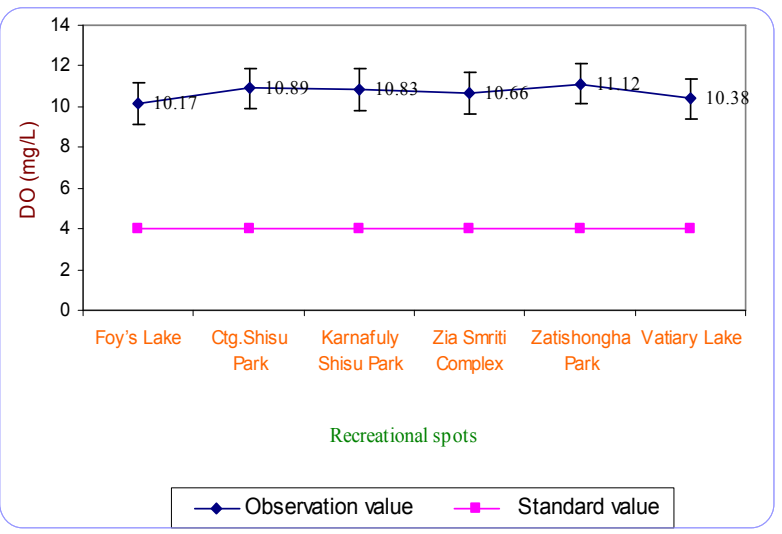

Figure 5. DO in Water at Different Recreational Spots Compared with the Standard Value.

\subsubsection{Biological Oxygen Demand (BOD)}

The mean BOD value of the study areas varies in between 2.2 to $3.15 \mathrm{mg} / \mathrm{L}$, but all the observation were within the standard value $(8 \mathrm{mg} / \mathrm{L})$. The highest $(3.15 \mathrm{mg} / \mathrm{L})$ BOD was found in the water of Jatisongho Park while, the lowest $(2.20$ $\mathrm{mg} / \mathrm{L}$ ) was in Foy's Lake. The BOD of water of Chittagong Shisu Park, Karnafully Shisu Park, Zia Smriti Complex and Vatiary Lake were $2.90 \mathrm{mg} / \mathrm{L}, 3.07 \mathrm{mg} / \mathrm{L}, 2.53 \mathrm{mg} / \mathrm{L}$ and $2.34 \mathrm{mg} / \mathrm{L}$ respectively (Fig. 6). The water of all the recreational spots in the study area is safe as recreational water in respect of BOD. 


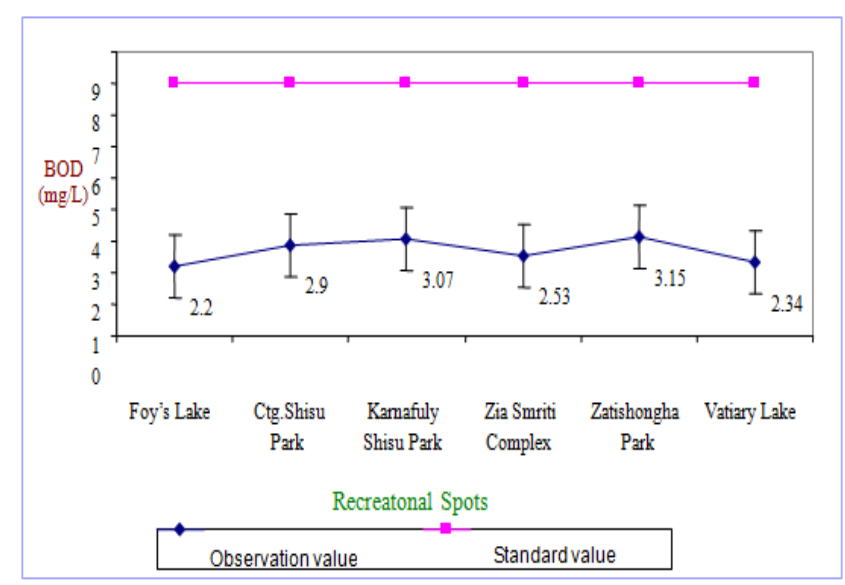

Figure 6. BOD of water at Different Recreational Spots Compared with the Standard Value.

\subsubsection{Chemical Oxygen Demand (COD)}

Water of three recreational spots maintained the acceptable level $(200 \mathrm{mg} / \mathrm{L})$, in contrary; other three spots exceeded the acceptable level. The highest $(467.60 \mathrm{mg} / \mathrm{L})$ value of COD was found in the water of Zia Smriti Complex followed by Karnafully Shisu Park (334 mg/L) and Chittagong Shisu Park (334 mg/L) (Fig. 7). However, COD of other three spots namely; Foy's Lake $(66.8 \mathrm{mg} / \mathrm{L})$, Vatiary Lake $(66.8 \mathrm{mg} / \mathrm{L})$ and Jatisongho Park $(133.6 \mathrm{mg} / \mathrm{L})$ was lower than standard limit.

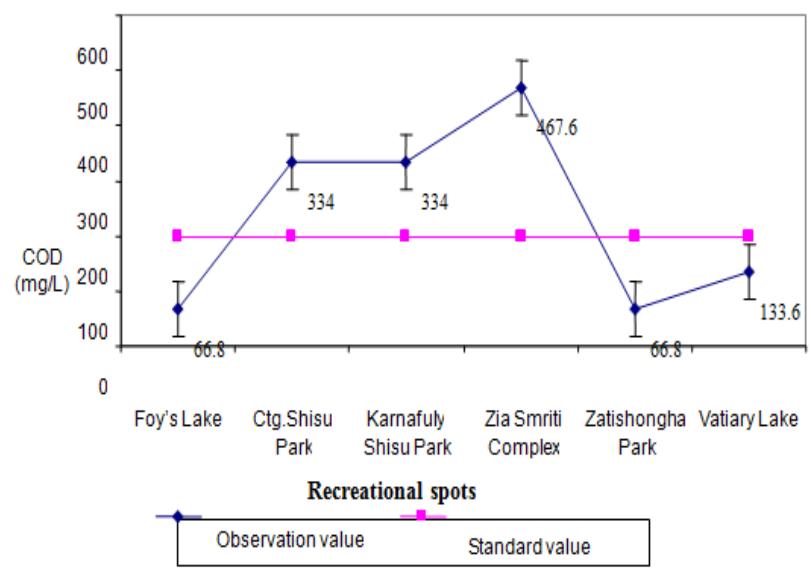

Figure 7. COD of Water at Different Recreational Spots Compared with the Standard Value.

\subsubsection{Sulfate}

The observation value of sulfate in the water is lower than that of the standard value. The lowest $(195 \mathrm{mg} / \mathrm{L})$ value was found in Foy's Lake water. The highest $(246.67 \mathrm{mg} / \mathrm{L})$ value was found in the water of Chittagong Shisu Park followed by Jatisongho Park (231.67 mg/L), Karnafully Shisu Park $(223.33 \mathrm{mg} / \mathrm{L})$, Zia Smriti Complex $(213.33 \mathrm{mg} / \mathrm{L})$ and Vatiary Lake (205 mg/L) respectively (Fig. 8). Considering sulfate standard in recreational water the study revealed that the recreational spots possess lower sulfate value compared to standard value $(400 \mathrm{mg} / \mathrm{L})$ and hence, is acceptable.

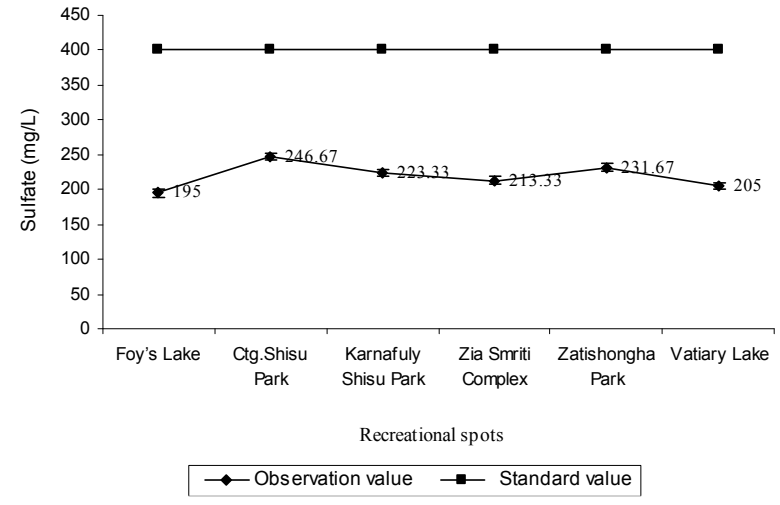

Figure 8. Sulfate of Water at Different Recreational Spots Compared with the Standard Value.

\subsubsection{Nitrate}

The highest $(19.33 \mathrm{mg} / \mathrm{L})$ concentration of nitrate was observed in the water of Chittagong Shisu Park, which is almost twice than standard value $(10 \mathrm{mg} / \mathrm{L})$. Fortunately, the presence of nitrate in the water of Karnafully Shisu Park, Zia Smriti Complex, Jatisongho Park and Vatiary Lake was zero (Fig. 9). Moreover, in Foy's lake water only $3 \mathrm{mg} / \mathrm{L}$ nitrate was present which is also lower than standard limit. Higher amount of nitrate was found due to the presence of increasing rate of organic waste, inorganic compounds from agricultural fields and mineral salts such as $\mathrm{NH}_{4} \mathrm{NO}_{3}$, $\mathrm{NaNO}_{3}, \mathrm{KNO}_{3}$ and $\mathrm{CaNO}_{3}$ from salt made products. These salts are separated as ions and hence, increased amount of $\mathrm{NO}_{3}$ was found in the water of Chittagong Shisu Park. Therefore organic wastes, inorganic compounds and mineral salts should be kept in control to safe use of water for recreational purposes. On the other hand, water of other five recreational spots is congenial for recreational purpose.

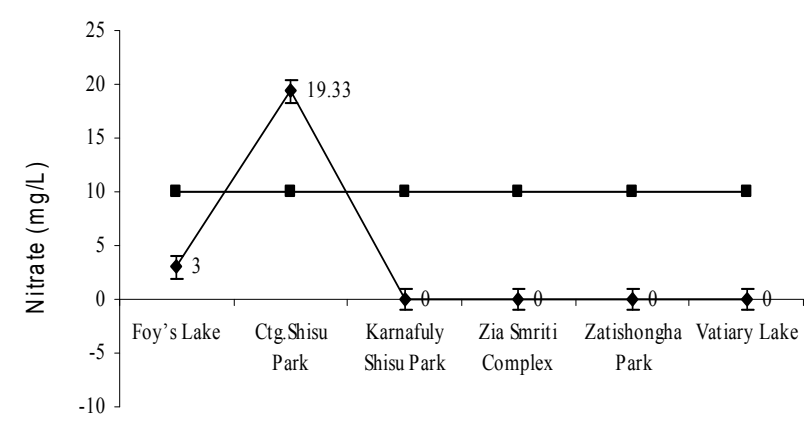

Recreational Spots

$\rightarrow$ Observation value $\quad \rightarrow-$ Standard value

Figure 9. Nitrate of Water at Different Recreational Spots Compared with the Standard Value.

\section{Conclusion and Recommendation}

\subsection{Conclusion}

Water is the elixir of life. It can be used various purposes depending on unique standard for each uses. Results of 
different experiments on recreational water in different parts of the world exhibited that recreational water is safe when it maintains the standard value but when standard is exceeded it generates significant number of water borne diseases. In our study it was found that none of six spots maintained the standard of every parameter. If these sorts of scenario are continued the ultimately people of Chittagong will be affected by water borne diseases. In our experiment, the water quality parameters $\mathrm{pH}$, DO, BOD, COD, Sulphate, Nitrate, Conductivity, Color, Odor, Turbidity were determined for analyzing whether all of the spots maintain the recreational water standard or not. Unfortunately, the experiment depicted that most of the recreational spots exceeded the standard value of conductivity except Karnafully Shisu Park. In case of Turbidity except Foy's Lake, other five recreational spots contained lower value than the standard value, which indicates that, the suitability of water for recreational purposes. However, water of five recreational spots except Foy's Lake, are suitable for recreational uses in respect of color. Two recreational spots provided odorous breathtaking. Moreover, in respect of $\mathrm{pH}$, water of all of the recreational spots is congenial for recreational purposes. From the observation value of BOD it can be concluded that water of all the recreational spots is congenial as recreational water. COD was higher at Chittagong Shishu Park, Karnafully Shishu Park and Zia Smriti Complex. Nitrate value was also satisfactory except Chittagong Shisu Park. Biological parameters couldn't determine in the experiment. It is also mentioned here that only these parameters cannot make water suitable for recreation as biological parameters as well other physical and chemical parameters are important factors for recreational purposes. So for the safety of public health, these unwanted levels of different physical and chemical parameters should be maintained on an urgent basis.

\subsection{Recommendation}

It may recommend that necessary steps and care should be taken by the concerned authority immediately to ensure the maintenance of the quality of recreational water in Chittagong. Otherwise, hazards to human may arise in the respective areas.

- People should be aware of the standard of recreational water for their own interest.

- More researches on recreational water resource protection management have to be initiated.

- Care should be taken so that any waste not to be discharged into recreational water nearby.

- Lead agency to be set up to coordinate water related organizations and for recreational water quality control, management and planning.

- Restoration and protection of potential sites should be carried out.

- Blocked or threatened water reservoir should be urgently cleaned and managed through appropriate technology.

\section{References}

[1] Bhandari. B.B., 2003. "What is happening to our Freshwater Resources? Institute for Global Strategies. Environmental Education project". Tokyo.

[2] United Nations Food and Agriculture Organization (UNFAO), 2007. "Coping With Global Water Scarcity". Rome, FAO.

[3] Agrawal, K.C. 1993. Environmental Biology. New Delhi, India. 250p.

[4] Shamsad, S.Z.K.M., Islam, M.S., Hassan, M.Q., 1999. Ground water quality and hydrochemistry of Kushtia district, Bangladesh. J. Asiat. Soc. Bangladesh, Sci. 25(1):1-11.

[5] Hatfield J.L., Karlen D.L., 1994. Sustainable Agricultural Systems. Lewis Publishers. Boca Raton, Florida. USA, pp. 21-46.

[6] Doanhue, R.L., Miller, R.W., Shickluna, J.C., 1999. Soils: An Introduction to Soils and Plant Growth. $5^{\text {th }}$ ed., Prentice-Hall of India (pvt.) Ltd. New Delhi, pp. 450-465.

[7] Manahan, S.E., Environmental Chemistry. CRL Press Inc. Boca Raton, USA-1994, pp.179-200

[8] Peavy, H.S., Rowe, D.R., Tchobanoglous, G., 1985. Environmental Engineering. McGraw Hill, New York, pp. 14-56.

[9] Gupta, P. K., 2000. Methods in Environmental Analysis: water, Soil and Air. Agrobios (India), Jodhpur, pp. 5-76.

[10] Trivedi, P.R., Raj, G., 1992. Encyclipedia of Environmenatal Sciences. Vol. 8. Anmol Publication (pvt) Ltd, New Delhi.311p.

[11] Siddiqui, M.H., 1992. Water Resource Development in Bangladesh, Technology and Environment. 8:(4):41-51.

[12] Ahmed, A.1999. Safe Water Supply Environmental Problems and Stratgies. Environmental Development and Management, Ed. by Pandy.

[13] Solaiman, M., 2005. Green Star Publication, Chittagong, Bangladesh, 51p.

[14] Hossain, Md.L., Islam, K.S., 2013. Assessment of Water Quality in Chandpur District of Bangladesh. Journal of Environmental Treatment Techniques, 1(2):91-100.

[15] Shamsad, S.Z.K.M., Islam, K.Z., Mahmud, M.S., Hakim, A., 2014. Surface Water Quality of Gorai River of Bangladesh. Journal of Water Resources and Ocean Science. 3(1)1:10-16. doi: $10.11648 /$ j.wros.20140301.13.

[16] Rahman, A.A., Huq, S., Conway, G.R., 2000. Environmental Aspect of Surface Water system of Bangladesh. The University Press Limited, Dhaka, pp. 7-265.

[17] Islam, M.S., Hasan, M.Q., Shamsad, S.Z.K.M., 1998. Quality of irrigation water in the Kushtia District of Bangladesh. $J$. Biol. Sci. 7(2):129-138.

[18] De, A.K.. 2000. Environmenatal Chemistry. New Age International Publishers, India. 242-244p. 
[19] Hussain, A., 2006. Pond Water Quality of Sandwip Island. B. Sc (Hons.). Project paper, Institute of Forestry and Environmental Sciences, University of Chittagong, Bangladesh.1-2p.

[20] Canadian guidelines for recreational water quality. Part-1. (http://www.hc-sc.gc.ca/Last Retrived on 01 July, 2008).

[21] Sunger, N., Teske, S.S., Nappier, S., Haas, C.N. 2012 Recreational use assessment of water-based activities, using time-lapse construction cameras. Journal of Exposure Science and Environmental Epidemiology, 22:(281-290), doi:10.1038/jes.2012.4

[22] Islam, S., 2003. Banglapedia: National Encyclopedia of Bangladesh. Asiatic Society of Bangladesh, Nimtali, Dhaka, Bangladesh. PP 515.

[23] Hossain, Md.L., Das, S.R., Hossain, M.K., 2014. Impact of Landfill Leachate on Surface and Ground Water Quality. Journal of Environmental Science and Technology. (Accepted).

http://scialert.net/onlinefirst.php?issn=1994-7887. doi: $10.3923 /$ jest.2014

[24] Chittagong Development Authority (CDA), 1992. Preparation of structural plan, master plan and detailed area plan for Chittagong (UNDP/UNHS project No. BGD/88/052), Chittagong, Bangladesh.
[25] Salam, M.A., Hossain, Md. L., Das, S.R., Wahab, R., Hossain, M.K., 2012. Generation and assessing the composition of household solid waste in commercial capital city of Bangladesh. International Journal of Environmental Science, Management and Engineering Research, 1(4):160-171.

[26] Bhuiyan. M.H., 2006. Outdoor Recreational Potentialities in Chittagong City.B.Sc. Project Paper submitted to the Institute of Forestry and Environmental Sciences, University of Chittagong, Bangladesh.29-44p.

[27] Khan, M.O., 1979. Cutting of hills: Lack of law or lack of law enforcement? The Daily star, The 15 June, Dhaka, Bangladesh.

[28] Olembo, R.J. and P.de. Rham. 1987. Urban forestry in two different worlds. Unasylva,39(155):2635 (http://www.fao.org/DOCREP/ARTICLE/WFC/XII/0347-B 5.HTM.

[29] WWF National surface water classification criteria 2007. Compiled by freshwater and toxics programme, WWF-Pakistan. http://www.cmc.sandia.gov/cmc-papers/sand2000-080 9.pdf 